\title{
The Effect of Recessions on Gambling Expenditures
}

\author{
Csilla Horváth · Richard Paap
}

Published online: 6 December 2011

(C) The Author(s) 2011. This article is published with open access at Springerlink.com

\begin{abstract}
This article examines the influence of the business cycle on expenditures of three major types of legalized gambling activities: Casino gambling, lottery, and parimutuel wagering. Empirical results are obtained using monthly aggregated US per capita consumption time series for the period 1959.01-2010.08. Among the three gambling activities only lottery consumption appears to be recession-proof. This series is characterized by a vast and solid growth that exceeds the growth in income and the growth in other gambling sectors. Casino gambling expenditures show a positive growth during expansions and no growth during recessions. Hence, the loss in income during recessions affects casino gambling. However, income shocks which are not directly related to the business cycle do not influence casino gambling expenditures. Pari-mutuel wagering displays an overall negative trend and its average growth rate is smaller than the growth in income, especially during recessions. The findings of this article provide important implications for the gambling industry and for local governments.
\end{abstract}

Keywords Gambling - Business cycle $\cdot$ Time series analysis · Cointegration

\section{Introduction}

Gambling is a major industry in the United States that experienced substantial growth in recent decades. Personal consumption expenditures from three major types of gambling (casino gambling, lottery, and pari-mutuel wagering) have reached \$50,291 billion by 1996 and this amount doubled by 2007. Commercial casino gambling has been referred to as one

C. Horváth $(\bowtie)$

Department of Strategy and Marketing, Institute for Management Research, Radboud University, P.O. Box 9108, 6500 HK Nijmegen, The Netherlands

e-mail: c.horvath@fm.ru.nl

R. Paap

Econometric Institute, Erasmus University Rotterdam, Rotterdam, The Netherlands

e-mail: paap@ese.eur.nl 
of America's fastest growing and most profitable industries for a long time (Siegel and Anders 2001). Lottery and pari-mutuel wagering activities experience steady, but somewhat slower expansion.

Due to the continuous expansion of gambling activities, revenue from legally sanctioned gambling has been playing an increasingly important role in states' overall revenues. From 1998 through 2007, such revenue represented a remarkably consistent 2.1-2.5\% of states' own-source revenues (Dadayan and Ward 2009) and gambling revenues were expected to keep rising.

However, after a long and steady increase, gambling and gambling revenues started to decline in 2008. In 2008, revenue in the national commercial casino sector dropped about $4.7 \%$ compared to 2007 . The trend has continued in the first months of 2009 . In fact, gross gaming revenues went down every month since February 2008 compared to the same month of the previous year, and as the recession got worse, monthly revenue decreases have become more significant (American Gambling Association). This sudden and significant decline in casino gambling activity and revenue that occurred during the financial and economic crisis calls for understanding how gambling evolves during such difficult times.

While several aspects of gambling have been thoroughly investigated, the literature on relations between gambling and economic growth is scant ( $\mathrm{Li}$ et al. 2010). There is very little understanding about how the general conditions of the economy influence gambling activities and only very few studies investigate whether and how gambling activities are influenced by the economic crisis. The studies that look into this problem analyze the effect of the 1997-1998 Asian financial crisis on Las Vegas casino drops of baccarat and pai gow, two games favored and mainly played by Asians (Gu 1999; Raab and Schwer 2003). Gu (1999) finds that the Asian crisis had a severe impact on Asian players' gaming propensity for both games. In line with this, Raab and Schwer (2003) find a temporary decline in baccarat wins due to the Asian crisis; however, their model's findings suggest this effect dies out over time.

While these articles call attention to the possible serious consequences of crises on gambling, they have a few drawbacks. First, they investigate the impact of one single crisis on gambling activities. Second, their analysis focuses on quite specific and local ways of gambling (baccarat and pai gow). Such specificities of the setup of the research give doubt to the generalizability of the results. Third, the authors rely on rather short periods of data in their analysis, the period of 1997-1998. To detect significant changes in gambling patterns one needs longer time series. Finally, the authors do not utilize important techniques, such as unit root and cointegration tests that are prerequisites of proper modern time series analysis (Hamilton 1994).

Insights in changes in gambling activities during recessions are useful for several parties. They help gambling industries with the optimal allocation of their resources during the downturn. These involve decisions about personnel, supply of snacks and drinks, and promotional activities, among other things. They also help local governments in predicting the evolvement of one of their major tax revenues during the downturn (Cargill and Eadington 1978) and they provide support for decisions on expanding their gambling operations for balancing their budgets (Dadayan and Ward 2009).

In this article we analyze the effect of financial and economic crisis on gambling activities using time series analysis. We investigate the pattern in aggregate monthly US expenditures on three major gambling activities (i.e. casino gambling, lottery, and parimutuel wagering) across the business cycle and compare the results with consumption of other goods and services. The sample period under consideration (1959.01-2010.08) covers several economic and financial crises and is long enough for conducting reliable 
analyses. Finally, we utilize modern time series techniques for the analyses, including testing for (common) stochastic trends.

The outline of the remainder of this paper is as follows. Section "Determinants of gambling behavior during the recession" deals with the theoretical background of factors that may influence gambling behavior during recessions. Section "Data and analysis" describes the data, the empirical analysis, and the empirical findings. Section "Discussion" provides a discussion of the results and Section "Conclusions" concludes.

\section{Determinants of Gambling Behavior During the Recession}

Economic and financial crises generally result in rising unemployment and cuts in wages and salaries. The reduced income may persuade people to decrease their general consumption, including their gambling expenditures. Indeed, earlier studies, including those by DeBoer (1986) and Mikesell and Zorn (1987) find lottery sales to be positively influenced by income and Mikesell (1994) discover that real income elasticity of lottery sales is much greater than for other state-local revenues. On the other hand, according to the permanent-income hypothesis (PIH) of Friedman (1957) households look into the future in deciding the amount of current consumption. By doing this, their consumption is determined by their long-term income expectations, rather than by temporary, short-run changes in their current income. Since long-term expectations are usually quite stable over time, the $\mathrm{PIH}$ implies that consumers smooth their consumption and keep it at the level that corresponds to their permanent income. As a result, business-cycle-induced fluctuations in income which people see as temporary will have little effect on their gambling expenditures, and income should rather have a long-run relationship with consumption.

One of the main criticisms of the PIH is the assumption that consumers and households are rational and that they base their decisions about how much to consume on purely rational and economic considerations. The psychology literature, however, shows that this may not necessarily be true and that emotional and contextual factors may alter consumption patterns as well. Below, other factors that may influence gambling consumption during recessions are discussed.

A crisis brings about uncertainty and anxiety into society. People face an increasing fear of losing their job and those fired undergo the pressure of having to find new employment when the job market stagnates. Anxiety and stress have been shown to be positively correlated to gambling behavior. The strength model predicts that simultaneous attempts at self-control (such as trying to avoid gambling while also coping with stress) may lead to poorer self-control overall (Muraven and Baumeister 2000). This is because adapting to stress consumes self-control strength, resulting in poorer subsequent self-control performance (Glass et al. 1969). Emotional stress arising from difficulties is often associated with problem gambling and reports of problem gamblers reveal that gambling intensity is highest during periods of emotional stress (Sharpe and Tarrier 1993). Additionally, Lightsey and Hulsey (2002) find that outside factors such as stress may be likely to contribute to gambling problems.

Unemployment will also lead to a significant increase in spare time; most of which is likely to be spent at homes. Boredom plays an important factor in the development and maintenance of problematic gambling behavior. In interviews gamblers indicate that boredom is among the primary motivators for engaging in gambling activity (e.g. Brown 1986; Mercer and Eastwood 2010) and researchers regularly report a positive relationship between gambling problems and self-report measures of boredom (e.g. Blaszczynski et al. 
1990; Bonnaire et al. 2004; Nower and Blaszczynski, 2006). Additionally, studies indicate that older adults (65+), whose daily activities might be the most similar to an unemployed citizens, are more likely to gamble for stimulation and for relieving boredom rather than for winning money (Clarke 2008; Hope and Havir 2002; McNeilly and Burke 2002; Wiebe and Cox 2005).

Mikesell (1994) reports a positive effect of a recession on gambling. Gambling offers a pure chance opportunity to win a jackpot, often multiple millions of dollars for the best modern lotto games, for a small price. In difficult economic times more people may find this tiny but real chance of winning a huge prize more attractive than in less turbulent times (Mikesell 1994). The author finds that lottery sales are sensitive to the state unemployment rate, increasing by about $0.17 \%$ for each $1 \%$ increase in that rate.

Recession may also cause an increase in gambling opportunities. When normal revenue growth softens during economic downturns, states often consider expanding their gambling operations for balancing their budgets (Dadayan and Ward 2009) by efforts to keep gambling revenues (and the concomitant gambling taxes) within the state, to reduce unemployment, and to attract tourism or "export taxes" (Calcagno et al. 2010; Richard 2010). Richard (2010) conducts a study to find the factors behind the spread of casino gambling in 13 nations around the world. He finds that economic development needs, as measured by general unemployment rates, are associated with the casino legalization decisions by national governments. Casino legalizations decisions are more likely to occur in the years with high unemployment.

In sum, it is unclear how gambling activities are affected by the recession; while several mechanisms suggest an increase, others imply a decrease in this period. The limited empirical findings are similarly confusing. While Tenkel (1970) provides anecdotal evidence that during the Great Depression there was an upswing in betting on horses and numbers, analyses about the effect of the Asian crisis (Gu 1999; Raab and Schwer 2003) indicate a decrease in gambling due to the downturn.

This paper addresses how gambling consumption is related to temporary changes in income due to recessions and whether income and gambling may have a long-run relationship as suggested by the PIH. The empirical analysis uses Sargent's (1978) assumption that the annuity value of future capital income is equal to the value of real financial wealth and uses disposable income as a proxy for wealth (Morley 2007; Palumbo et al. 2006). Additionally, the article compares changes in gambling expenditures across the business cycle to changes in consumption patterns in other sectors using aggregated time series data from the United States.

\section{Data and Analysis}

Data

To investigate the relation between gambling consumption and the business cycle, total gambling, casino gambling, lottery, and pari-mutuel wagering consumption expenditures together with the corresponding price indices are obtained from the Bureau of Economic Analysis (BEA). For comparison, we also consider time series of nondurable, service, and recreational consumption expenditures, and of disposable income from the same source. All consumption series are seasonally adjusted and made real using the corresponding price indices and divided by US population obtained from the St. Louis FED. These transformations result in real per capita consumption and income series. We use the 
business cycle peak and through dates from the National Bureau of Economic Research to construct a business cycle indicator $s_{t}$, which is a $0 / 1$ time series, being equal to 1 if time $t$ corresponds to a recession and 0 otherwise.

\section{Procedure}

We start the empirical analysis with the general procedure of analyzing relationships using time series data. The first step of this procedure requires considering necessary transformations for the series. This usually concerns logarithmic transformation, and determining the statistical properties of the trend in the times series using unit root tests. The results of this test determine whether the series need to be differenced or de-trended for proper inference.

After this necessary procedure, we can start the empirical investigation of how gambling consumption evolves over the business cycle. As a first step of this analysis, we investigate whether growth rates of gambling and other consumption are different during expansion and recession using a linear regression model. In this model we regress the growth rates of the series on the business cycle indicator. With regard to the consumption series for which the results show significant differences, the next question is whether the differences can be related to variation in income over the business cycle, that is, whether the consumption patterns over the business cycle closely follow income. A close evolution would mean that people adjust their consumption to temporary and probably unexpected changes in income, which implies the rejection of the PIH. After having established how the consumption series react to shocks due to the business cycle, the next step is to analyze whether changes in income, which are not due to changes in the business cycle effect consumption differently. To answer this question we investigate the presence of a long-run stable relationship between (gambling) consumption and income.

\section{Analysis and Results}

To get an understanding about the pattern in the per capita series, the time series are plotted against time for the sample period 1959.01-2010.08, see Fig. 1. As can be observed from the plots, many time series display a trending pattern. Almost all series show growth in the period under scrutiny and in many cases the growth is exponential. The only exception is pari-mutuel wagering, in which an overall declining trend can be observed.

\section{Considering Necessary Transformations for the Series}

As common in the time series literature, we transform the series using a logarithmic transformation. This transformation has two advantages. First, exponential growth becomes linear growth. Second, the first differences of the log transformed series correspond to growth rates.

\section{Determining the Statistical Properties of the Trend in a Times Series}

Regressions involving trending time series can lead to spurious results if the trend is not accounted for in an appropriate way (Granger and Newbold 1974). For example, two series both with a positive trend are always positively correlated even if there is no causal relation between the series. Hence, for proper inference on the relation among gambling, income, 
Casino gambling

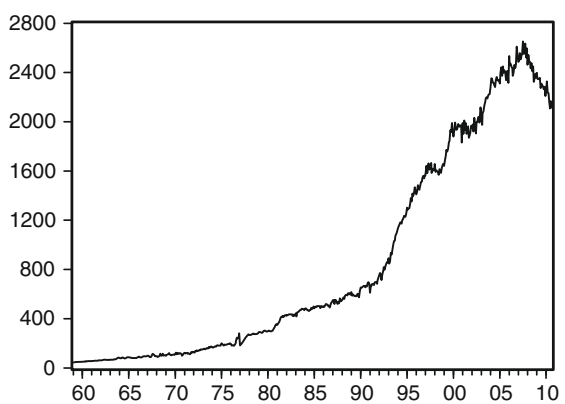

Pari-mutuel wagering

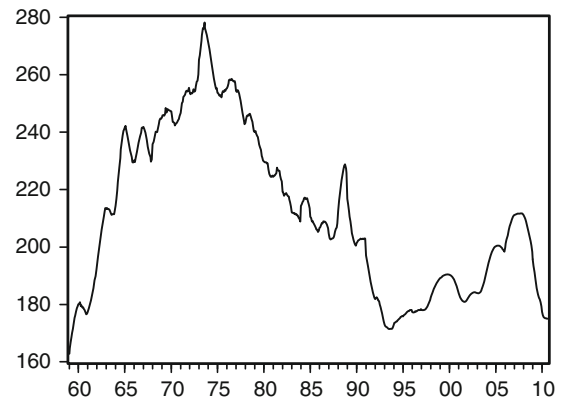

Recreational consumption

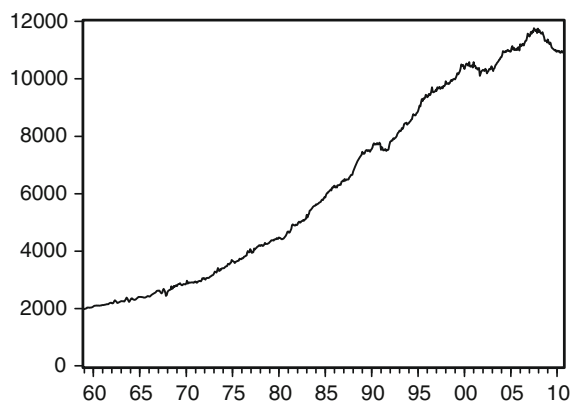

Nondurable consumption

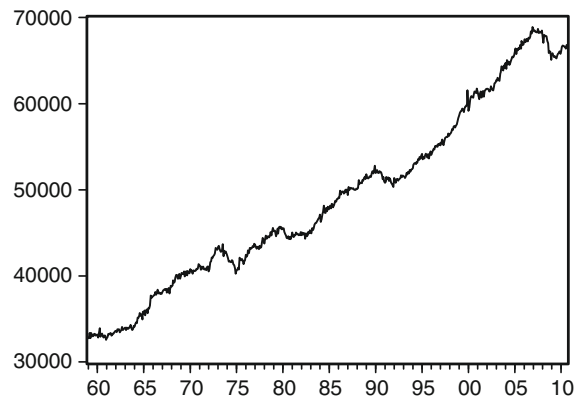

Lottery gambling

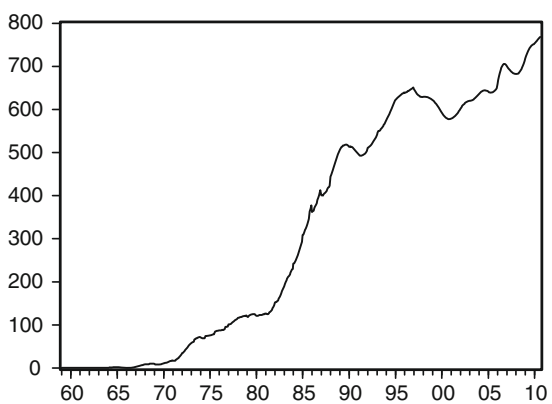

Total gambling

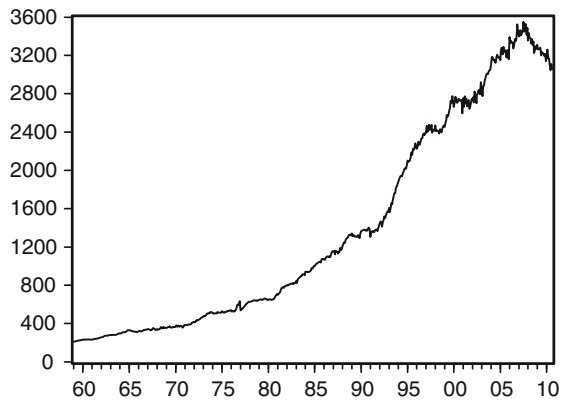

Service consumption

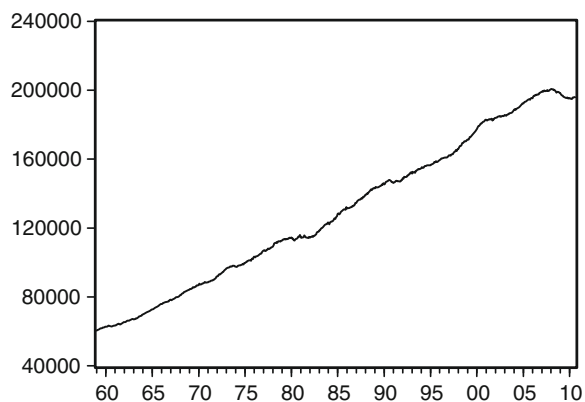

Disposable income

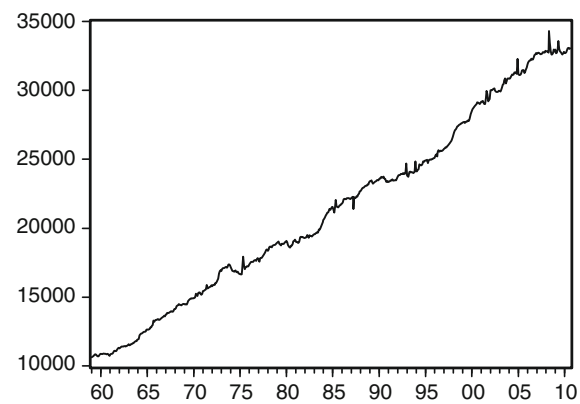

Fig. 1 Time series plots of the consumption series: 1959.01-2010.08 
and the business cycle, first the statistical properties of the trend in the times series need to be determined. Time series can contain a stochastic trend (integrated time series), a deterministic trend, or both (Hamilton 1994). Stochastic trends can only be removed by taking first differences of the time series. Deterministic trends can be accounted for by including a linear time trend in time series models.

To test for the presence of a stochastic trend in a time series $y_{t}$ the Dickey-Fuller (1979) test is applied, which amounts to estimating the following regression model:

$$
\Delta y_{t}=\mu+\tau t+\alpha y_{t-1}+\phi_{1} \Delta y_{t-1}+\cdots+\phi_{p} \Delta y_{t-p}+\varepsilon_{t},
$$

where $\Delta y_{t}=y_{t}-y_{t-1}, \varepsilon_{t}$ is the error term for $t=1, \ldots, T$, and $\mu, \tau, \alpha, \phi_{1}, \ldots, \phi_{p}$ are parameters. The Dickey-Fuller test procedure concerns testing the null hypothesis $\alpha=0$ using a $t$-test. In case $\alpha=0$, the series contains a stochastic trend and for proper inference first differences of the time series need to be considered. As the series are trending, the regression contains a deterministic trend $(t)$ and an intercept $(\mu)$. The asymptotic distribution of the $t$-test statistic is not standard and hence different critical values need to be used, see, for example, Hamilton (1994) for details. The lag order $p$ in the regression model can be determined using the famous Bayesian Information Criterion (BIC) of Schwartz (1978) for model selection.

Table 1 displays the test results for all times series under consideration. The results indicate that the restriction $\alpha=0$ cannot be rejected for all series. Hence, first differences of the times series $\left(\Delta y_{t}\right)$ need to be considered for proper statistical inference. As the series are $\log$ transformed, the first differences equal the growth rates.

\section{Differences in Growth Rates During Expansion and Recession}

To investigate whether growth rates of gambling and other consumption series are different during expansion and recession, we estimate a linear regression model, in which the growth rates of the series are regressed on the business cycle indicator $\left(s_{t}\right)$ :

$$
\Delta y_{t}=\beta_{0}\left(1-s_{t}\right)+\beta_{1} s_{t}+\eta_{t},
$$

where $\eta_{t}$ is the error term, $\beta_{0}$ corresponds to the growth rate during expansion, and $\beta_{1}$ to the growth rate during recession. Table 2 displays the estimates of the $\beta$ parameters together with their standard errors for all the time series. The standard errors are robust and, hence, corrected for possible heteroscedasticity and correlation in the residuals (Newey and West 1987). The estimation results indicate higher growth rates during expansion periods than during recessions for all series.

Table 1 Unit root test results; sample: 1959.01-2010.08

Test regression is Eq. 1

\begin{tabular}{lcll}
\hline Variables & ADF test values & $P$ value & Lag length \\
\hline Casino & -0.01 & 0.996 & 4 \\
Lottery & -0.83 & 0.961 & 4 \\
Pari-mutuel wagering & -2.89 & 0.164 & 3 \\
Total gambling & 0.40 & 0.999 & 1 \\
Recreational & 2.31 & 1.000 & 4 \\
Service & 1.45 & 1.000 & 1 \\
Nondurables & -1.80 & 0.705 & 2 \\
Disposable income & -1.28 & 0.892 & 3 \\
\hline
\end{tabular}


Table 2 Growth rate results across the business cycle, sample: 1959.01-2010.08

\begin{tabular}{lllllrlrlrl}
\hline & $\beta_{0}$ & SE & $T$ value & $P$ value & \multicolumn{1}{l}{$\beta_{1}$} & SE & $T$ value & $P$ value & Wald & $P$ value \\
\hline Casino & 0.727 & 0.12 & 5.89 & 0.00 & 0.010 & 0.26 & 0.04 & 0.97 & 5.82 & 0.02 \\
Lottery & 1.277 & 0.55 & 2.32 & 0.02 & 1.064 & 0.36 & 2.93 & 0.00 & 0.11 & 0.75 \\
Pari-mutuel & 0.079 & 0.05 & 1.68 & 0.09 & -0.368 & 0.07 & -4.89 & 0.00 & 26.50 & 0.00 \\
$\quad$ wagering & & & & & & & & & & \\
Total gambling & 0.519 & 0.06 & 8.71 & 0.00 & -0.051 & 0.10 & -0.46 & 0.64 & 20.87 & 0.00 \\
Recreational & 0.320 & 0.03 & 9.88 & 0.00 & 0.028 & 0.08 & 0.33 & 0.74 & 10.54 & 0.00 \\
Service & 0.217 & 0.01 & 17.86 & 0.00 & 0.034 & 0.04 & 0.85 & 0.40 & 19.69 & 0.00 \\
Nondurables & 0.160 & 0.02 & 7.98 & 0.00 & -0.137 & 0.06 & -2.16 & 0.03 & 19.20 & 0.00 \\
Disposable & 0.225 & 0.02 & 9.95 & 0.00 & -0.052 & 0.06 & -0.84 & 0.40 & 17.34 & 0.00 \\
$\quad$ income & & & & & & & & & & \\
\hline
\end{tabular}

Equation 2: $\beta_{0}$ growth rate during expansion, $\beta_{1}$ growth rate during recession The null-hypothesis of the Wald test is: $\beta_{0}=\beta_{1}$

The final two columns of Table 2 show the Wald statistics with corresponding $P$ values. This statistic tests the restriction that the growth rates during expansions and recessions are the same $\left(\beta_{0}=\beta_{1}\right)$. This restriction is clearly rejected for all but the lottery expenditures series. The results in Table 2 imply that in general the growth rates in consumption and income are significantly lower during recessions than expansions. The only exception is expenditures on lotteries, for which the results reveal a vast and solid growth that is independent of the business cycle supporting the PIH.

\section{The evolution of Consumption and Income Over the Business Cycle}

With regard to the consumption series for which the results show significant differences in growth during expansion and recession, the next question is whether these differences can exclusively be related to variation in income. The following regression model addresses this issue:

$$
\Delta \text { Cons }_{t}-\Delta \text { Inc }_{t}=\kappa_{0}\left(1-s_{t}\right)+\kappa_{1} s_{t}+\eta_{t},
$$

where $\eta_{t}$ is the error term and $\kappa_{0}$ corresponds to the difference in growth rate between consumption and income during expansions and $\kappa_{1}$ to the difference in growth rate during recessions. Table 3 displays the estimates of the $\kappa$ parameters together with their robust standard errors for all time series under consideration.

Concerning the co-evolution of the consumption series and income, an important question is whether $\kappa_{0}=\kappa_{1}=0$. The final two columns of Table 3 show the F-statistics for this restriction with corresponding $p$-values. The existence of this relationship means that growth rates in consumption are the same as the growth rates in income, and hence, the consumption rate fully reacts to temporary changes in income. This either implies the rejection of the $\mathrm{PIH}$ for this consumption series or that people adjust their expectations about future income during recessions. According to Table 3, services seem to exhibit this behavior.

In case the $\kappa_{1}$ parameter equals zero and $\kappa_{0}$ is positive, the growth rates in consumption are higher than the growth rates in income during expansions and the growth rates are the same during recessions. Consumption again reacts to the business cycle but even more than 
Table 3 Difference in growth rates between consumption and income across the business cycle, sample: 1959.01-2010.08

\begin{tabular}{|c|c|c|c|c|c|c|c|c|c|c|}
\hline & $\kappa_{0}$ & SE & $T$ value & $P$ value & $\kappa_{1}$ & SE & $T$ value & $P$ value & $F$ test & $P$ value \\
\hline Casino & 0.503 & 0.13 & 4.03 & 0.00 & 0.061 & 0.27 & 0.23 & 0.82 & 8.22 & 0.00 \\
\hline $\begin{array}{c}\text { Pari-mutuel } \\
\text { wagering }\end{array}$ & -0.146 & 0.05 & -3.13 & 0.00 & -0.316 & 0.10 & -3.27 & 0.00 & 10.31 & 0.00 \\
\hline $\begin{array}{l}\text { Total } \\
\text { gambling }\end{array}$ & 0.295 & 0.06 & 4.75 & 0.00 & 0.001 & 0.12 & 0.01 & 0.99 & 11.33 & 0.00 \\
\hline Recreational & 0.096 & 0.04 & 2.54 & 0.01 & 0.080 & 0.11 & 0.74 & 0.46 & 3.51 & 0.03 \\
\hline Service & -0.007 & 0.02 & -0.34 & 0.73 & 0.086 & 0.07 & 1.31 & 0.19 & 0.90 & 0.41 \\
\hline Nondurables & -0.085 & 0.06 & -1.35 & 0.17 & -0.065 & 0.02 & -2.70 & 0.01 & 5.23 & 0.01 \\
\hline
\end{tabular}

Equation 3: $\kappa_{0}$ growth rate difference during expansion, $\kappa_{1}$ growth rate difference during recession The null-hypothesis of the $F$ test is: $\kappa_{0}=\kappa_{1}=0$

in the previous situation where $\kappa_{0}=\kappa_{1}=0$. Table 3 shows that this situation holds for casino, total gambling, and recreational consumption.

A similar conclusion can be drawn if the $\kappa_{0}$ parameter is zero and the $\kappa_{1}$ parameter is negative, which is the case for nondurable consumption. Now, the growth rate in consumption is the same as the growth in income during expansions but smaller during recessions. The growth rate in pari-mutuel wagering is lower than the growth rate in income both during recessions and expansions although the difference is larger during recessions.

\section{Cointegration Relations}

The test results show that apart from lottery expenditures, all consumption series are influenced by business cycle fluctuations. Assuming that changes in income during recessions are seen to be temporary, this implies that the PIH is not supported. The question that remains is whether changes in income which are not due to changes in the business cycle affect consumption differently than those of the business cycle. In other words, does the PIH hold after correcting for business cycle fluctuations. Campbell (1987) shows that if income has a stochastic trend the PIH implies a long-run stationary relationship between consumption and income. Hence, the consumption series and the income series must share a common stochastic trend. A common stochastic trend means that there exist a long-run relation between the consumption series and the income series which does not contain a stochastic trend. This phenomenon is known as cointegration, see Engle and Granger (1987) and the corresponding relation between consumption and income is called a cointegration relation.

We apply the Engle and Granger two-step approach to test for common stochastic trends (i.e. cointegration) between our income and consumption series. The first step amounts to estimating the long-run relation using the regression:

$$
\text { Cons }_{t}=\gamma_{0}+\gamma_{1} \text { Inc }_{t}+\gamma_{2} s_{t}+u_{t},
$$

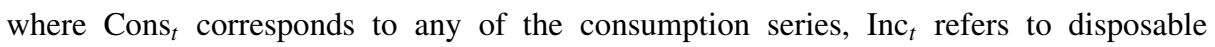
income, and $s_{t}$ may correct for level shifts in the relation between consumption and income during recessions. The second step concerns testing for the presence of a stochastic trend in the estimated residuals $\left(u_{t}\right)$ of Eq. 4 using the earlier introduced Dickey-Fuller test (see 
Table 4 Cointegration test results using Engle and Granger's two step approach, sample: 1959.01-2010.08

Dickey-Fuller test regression (Eq. 1) on the residuals of Eq. 4

\begin{tabular}{llll}
\hline Variables & EG test statistic & $P$ value & Lag length \\
\hline Casino & -2.28 & 0.02 & 1 \\
Lottery & -2.14 & 0.03 & 5 \\
Pari-mutuel wagering & -2.59 & 0.01 & 3 \\
Total gambling & -1.95 & 0.04 & 1 \\
Recreational & -1.96 & 0.04 & 0 \\
Service & -2.27 & 0.02 & 3 \\
Nondurables & -2.03 & 0.04 & 3 \\
\hline
\end{tabular}

Eq. 1). As the residuals of the regression have zero mean by construction, the DickeyFuller test equation now contains neither an intercept nor a trend. Table 4 displays the test results of this two-step approach with asymptotic $P$-values. According to the results the estimated relations between all $\log$ consumption and log income series contain no stochastic trend, indicating the presence of cointegration relations between the consumption and the income series.

\section{Long-run Relationships with Income}

The results in Campbell (1987) show that the $\gamma_{1}$ parameter in the long-run relation between consumption and income (Eq. 4) needs to be one for the PIH to hold. The next step in the analysis is therefore to test whether $\gamma_{1}$ equals 1 . This implies that the difference between the log consumption series and the log income series does not contain a stochastic trend. Unfortunately, standard $t$-test statistics for this restriction in the first-step regression (Eq. 4) are not valid. Therefore, we consider an-error correction model (Johansen 1995):

$$
\begin{aligned}
\Delta \text { Cons }_{t} & =\lambda_{0 c}+\lambda_{1 c} s_{t}+\lambda_{2 c} s_{t-1}+\delta_{c}\left(\text { Cons }_{t-1}-\gamma_{0}-\gamma_{1} \text { Inc }_{t-1}\right)+\text { lags }+v_{c t}, \\
\Delta \text { Inc }_{t} & =\lambda_{0 i}+\lambda_{1 i} s_{t}+\lambda_{2 i} s_{t-1}+\delta_{i}\left(\text { Cons }_{t-1}-\gamma_{0}-\gamma_{1} \text { Inc }_{t-1}\right)+\text { lags }+v_{i t},
\end{aligned}
$$

where the vector of error terms $\left(v_{c t}\right.$ and $\left.v_{i t}\right)$ are allowed to be correlated and lags denote lagged values of the $\Delta \operatorname{Cons}_{t}, \Delta \mathrm{Inc}_{t}$, and $s_{t}$ variables. The term $\left(\mathrm{Cons}_{t-1}-\gamma_{0}-\gamma_{1} \mathrm{Inc}_{t-1}\right)$ in Eqs. 5 and 6 contains the cointegration relation. The parameters of the error-correction model in Eqs. 5 and 6 are estimated using the maximum likelihood method; see Johansen (1995) for details.

Table 5 displays the results of the estimated $\gamma_{1}$ parameters. Except for pari-mutuel wagering expenditures, all parameters are positive. The third column of the table shows the likelihood ratio statistics for $\gamma_{1}=1$ and the fourth column the corresponding the $P$ values. Except for pari-mutuel wagering expenditures, the restriction $\gamma_{1}=1$ cannot be rejected which implies that the difference between the consumption and income series does not contain a stochastic trend. Pari-mutuel wagering expenditures do not seem to have a longterm relation with income. Hence, the PIH does not hold even after correcting for business cycle fluctuations. For the other series, the results suggest that consumption decisions are influenced by adjusted expectations about current and future income during recessions, but that other temporary shocks in income do not alter these expectations, see Paap and van Dijk (2003) for similar results. 
Table 5 Parameter estimates of the long-run relationship in the error-correction models, sample: $1959.01-2010.08$

Model is given in Eqs. 5 and 6

\begin{tabular}{lrlll}
\hline Variables & \multicolumn{1}{c}{$\gamma_{1}$} & LR $\left(\gamma_{1}=1\right)$ & $P$ value & Lags \\
\hline Casino & 5.797 & 2.558 & 0.11 & 4 \\
Lottery & 2.041 & 3.180 & 0.08 & 4 \\
Pari-mutuel wagering & -0.377 & 4.951 & 0.03 & 3 \\
Total gambling & 6.296 & 2.108 & 0.14 & 3 \\
Recreational & 0.503 & 1.012 & 0.31 & 4 \\
Service & 0.412 & 3.688 & 0.06 & 3 \\
Nondurables & 0.775 & 2.682 & 0.10 & 4 \\
\hline
\end{tabular}

\section{Discussion}

The results suggest that all series, except for the lottery consumption reveal some different growth pattern over the different stages of the business cycle. Exceptionally quick and steady growths in prevalence and scale of state lottery consumptions have been reported by several authors (Kearney 2005). Since the introduction of the first modern state lottery in New Hampshire in 1964 new states gradually implemented state lotteries in order to prevent cross-border lottery sales and to increase own state revenue. This expansion was supported by increased marketing of lotteries (Clotfelter and Cook 1987; Radding and Hume 1991) and by a growing interest of local governments and the public (Clotfelter and Cook 1987). As a result, government-sponsored lotteries have become a major source of government revenue (Clotfelter and Cook 1989; Miyazaki et al. 1998).

This observed steady increase in lottery consumption even during the recession can additionally be attributed to its low price. Lottery tickets typically cost a dollar. Because it is such an inexpensive product, it is probably not one of the first things that are cut from the regular monthly budget. Additionally, consumers with less discretionary dollars left at the end of their budget probably look for cheaper forms of entertainment than usually and would therefore be happy to try their chances by lottery. Economic hardships may, furthermore, prompt people to justify small-stakes gambles even as they cut back on nonessential goods and services. Lotteries can provide some hope to improve the overall circumstances significantly, for a reasonably low cost. Kearney (2005) finds that consumer demand for lottery products responds positively to the expected value of the gamble. The evaluation of a lottery winning and risk may be different in difficult times than in good times. Mikesell (1994) report that in difficult economic times more people may find the tiny real chance of winning a huge price offered by a lottery ticket more attractive than when unemployment rates are lower and traditional economic opportunities are brighter.

Our results show that during expansions casino consumption grows somewhat slower than lottery consumption, but faster than the consumption recreational activities, services, or nondurable products. However, during recession, this growth slows down significantly and is mainly driven by income growth. Authors report that during the recent downturn casino spending suffered more than the economy in general (see, for example, Rose 2010). The slower increase in casino consumption in recent times may be due to the fact that this industry is approaching its saturation point (Tripoli 2009). Additionally, the industry transformed going to casinos to a luxury entertainment that is usually coupled with a visit to exclusive restaurants or bars. This coupling may refrain people from casino gambling; while they may still want to gamble during recessions, they become less inclined to dine at top-quality restaurants. Finally, the introduction of the smoking ban may also have 
contributed to the decline in casino gambling expenditures in the past few years. Researchers point out that the ban hurts revenues (Garrett and Pakko 2009) and demand for casino gambling (Thalheimer and Ali 2008).

The other interesting finding is that while the gambling industry in general has been blooming, pari-mutuel wagering shows the lowest growth rate among all series, both during expansion and recession. Figure 1 even shows an overall declining trend for this series. This decline can be attributable to track closings, many as a result of the state giving preference to other types of gaming such as lotteries or casinos. Further factors may be the rising takeout rates and the increased availability of higher priced and exotic wagers (Mobilia 1992). Additionally, Mobilia (1992) finds evidence that the expansion of lotteries negatively affect attendance at tracks. Another potential non-economic reason for the decline is that horse racing is less appealing to younger people today than to their parents and grand-parents in the past. The younger generation tends to have shorter attention spans (Minon 2007). This does not favor wagering on horse racing as it requires detailed knowledge and time commitment (Shanklin 2010). Some support for this can be found in the results of Thalheimer (1998) who concludes that gamblers who wager also play video lottery terminal games but not the other way around.

Finally, the cointegration results suggest that the business cycle affects gambling consumption differently than other shocks to income. Results show evidence for consumption smoothing, once controlled for changes due to the business cycle. This outcome is in line with previous findings in the literature (Paap and van Dijk 2003; Hall et al. 1997). The results indicate that during possibly long-lasting periods of low economic activity people adjust their expectations about their current and future income, while temporary shocks in income which are not related to the business cycle do not alter these expectations.

\section{Conclusions}

This article analyses the effect of financial and economic crises on gambling activities using time series analysis. The effect of recessions on US aggregate expenditures of three major gambling activities (casino gambling, lottery, and pari-mutuel wagering) are investigated and the outcomes are compared to other economic consumption series, such as consumption of recreational activities, services, and nondurable goods.

The results indicate that the three gambling consumption series react quite differently to the business cycle. The only gambling sector that appears to be recession proof is lottery consumption. This series is characterized by a vast and solid growth that appears to be independent of the business cycle and of temporary shocks to income. Casino expenditures appear to have significant positive growth during both expansion and recession. This growth exceeds the growth in income during expansion but decreases and follows income growth closely during recession. Pari-mutuel wagering, on the other hand, shows no significant growth during expansion and reveals a decline during recession. In both periods the growth in this consumption series is significantly below the growth in income.

Compared to the evolution of consumption in other sectors, the growth in casino and especially lottery expenditures are found to be especially high during expansion. During recession the lottery consumption outperforms any other sector in terms of growth. At the same time, pari-mutuel wagering shows the weakest performance during both periods.

The expansion periods appear to stimulate people to increase their consumption of all aggregate consumption series; total gambling, recreational activities, services, and 
nondurables as well. The growth in the first two series even exceeds the growth in income, while consumption growth of services follows and of nondurables is below income growth in this period. During recession the consumption of total gambling and recreational activities does not change significantly but the consumption of nondurables reduces significantly, even more than the decline in income.

An additional important finding is that business cycle shocks influence most consumption series differently than other shocks.

\section{Implications}

Our analysis provides insights about gambling activities during recessions that are useful for several parties. According to the outcomes, during downturns, casino gambling and pari-mutuel are expected to experience a fall-back in demand and income. So, these industries should consider cutting back on (the hiring of) personnel, the supply of snacks and drinks, and adjust promotional activities, among other things. Such adjustments are not necessary for lotteries. The results of this article are also relevant for local governments that may expect some decline in tax revenues from these gambling sectors during the down-turn. Lotteries, however can provide a steady income for the local governments that is unaffected by the recession.

\section{Limitations and Future Research}

The results of this article suggest that among the three considered gambling activities only lottery consumption is recession-proof. The discussion section provides possible explanation for this phenomenon. However, further research is needed to fully understand the processes that drive and alter gambling expenditures during recession periods.

Additionally, the results of this article indicate that during possibly long-lasting periods of low economic activity people seem to adjust their expectations about their current and future income thereby influencing consumption, while other temporary shocks in income do not alter these expectations. An interesting line of research would be to analyze how people alter the expectations of their future income during recession. One could try to understand whether all consumers adjust their expectations or only those whose family is closely affected by the downturn and whether their (degree of) adjustment is related to characteristics of the business cycle and to personal or family characteristics, and finally, whether these expectations could be inflected by, for example, verbal interventions of the local or national government.

Open Access This article is distributed under the terms of the Creative Commons Attribution Noncommercial License which permits any noncommercial use, distribution, and reproduction in any medium, provided the original author(s) and source are credited.

\section{References}

Blaszczynski, A., McConaghy, N., \& Frankova, A. (1990). Boredom proneness in pathological gambling. Psychological Reports, 67(1), 35-42.

Bonnaire, C., Lejoyeux, M., \& Dardennes, R. (2004). Sensation seeking in a French population of pathological gamblers: Comparison with regular and nongamblers. Psychological Reports, 94(3), 1361-1371.

Brown, R. I. (1986). Arousal and sensation-seeking components in the general explanation of gambling and gambling addictions. International Journal of the Addictions, 21(9-10), 1001-1016. 
Calcagno, P. T., Walker, D. M., \& Jackson, J. D. (2010). Determinants of the probability and timing of commercial casino legalization in the United States. Public Choice, 142(1-2), 69-90.

Campbell, J. Y. (1987). Does savings anticipate declining labor income? Alternative test of the permanent income hypothesis. Econometrica, 55(6), 1249-1273.

Cargill, T. F., \& Eadington, W. (1978). Nevada's gaming revenues: Time characteristics and forecasting. Management Science, 24(12), 1221-1230.

Clarke, D. (2008). Older adults' gambling motivation and problem gambling: A comparative study. Journal of Gambling Studies, 24(2), 175-192.

Clotfelter, C. T., \& Cook, P. J. (1987). Implicit taxation in lottery finance. National Tax Journal, 40(12), 533-546.

Clotfelter, C. T., \& Cook, P. J. (1989). Selling hope: State Lotteries in America. Cambridge, MA: Harvard University Press.

Dadayan, L., \& Ward, R. B. (2009). For the first time, a smaller jackpot: Trends in state revenues from gambling. Albany: The Nelson A. Rockefeller Institute of Government.

DeBoer, L. (1986). Lottery taxes may be too high. Journal of Policy Analysis and Management, 5, 594-596.

Dickey, D. A., \& Fuller, W. A. (1979). Distribution of the estimators for autoregressive time series with a unit root. Journal of the American Statistical Association, 74(365), 427-431.

Engle, R. F., \& Granger, C. W. J. (1987). Co-integration and error correction: Representation, estimation, and testing. Econometrica, 55(2), 251-276.

Friedman, M. (1957). A theory of the consumption function. Princeton: Princeton University Press.

Garrett, T. A., \& Pakko, M. R. (2009). Casino revenue and the Illinois smoking ban. Federal Reserve Bank of St. Louis, working paper series. Working paper 2009-027A.

Glass, D. C., Singer, J. E., \& Friedman, L. N. (1969). Psychic cost of adaptation to an environmental stressor. Journal of Personality and Social Psychology, 12, 200-210.

Granger, C. W. J., \& Newbold, P. (1974). Spurious regressions in econometrics. Journal of Econometrics, 2, $111-120$.

Gu, Z. (1999). The Impact of the Asian financial crisis on Asian gaming activities: An examination of Las Vegas strip casino drops. Current Issues in Tourism, 2(4), 354-365.

Hall, S., Psaradakis, Z., \& Sola, M. (1997). Cointegration and changes in regime: The Japanese consumption function. Journal of Applied Econometrics, 12(2), 151-168.

Hamilton, J. D. (1994). Time series analysis. New Jersey: Princeton University Press.

Hope, J., \& Havir, L. (2002). You bet they're having fun! Older Americans and casino gambling. Journal of Aging Studies, 16(2), 177-197.

Johansen, S. (1995). Likelihood-based inference in cointegrated vector autoregressive models. Oxford: Oxford University Press.

Kearney, M. S. (2005). State lotteries and consumer behavior. Journal of Public Economics, 89(11-12), 2269-2299.

Li, G., Gu, X., \& Siu, R. C. S. (2010). The impacts of gaming expansion on economic growth: A theoretical reconsideration. Journal of Gambling Studies, 26(2), 269-285.

Lightsey, O. R., \& Hulsey, C. D. (2002). Impulsivity, coping, stress, and problem gambling among university students. Journal of Counseling Psychology, 49, 202-211.

McNeilly, D. P., \& Burke, W. J. (2002). Disposable time and disposable income: Problem casino gambling behavior in older adults. Journal of Clinical Geropsychology, 8(2), 75-85.

Mercer, K. B., \& Eastwood, J. B. (2010). Is boredom associated with problem gambling behaviour? It depends on what you mean by 'boredom'. International Gambling Studies, 10(1), 91-104.

Mikesell, J. L. (1994). State lottery sales and economic activity. National Tax Journal, 47(1), 165-171.

Mikesell, J. L., \& Zorn, C. K. (1987). Lottery sales: Separating the influence of markets and game structure. Growth and Change, 18(4), 10-19.

Minon, S. (2007). Generation Y and higher education: The other Y2 K. Journal of Institutional Research, $13(1), 24-41$.

Miyazaki, A. D., Hansen, A., \& Sprott, D. E. (1998). A longitudinal analysis of income-based tax regressivity of state-sponsored lotteries. Journal of Public Policy \& Marketing, 17(2), 161-172.

Mobilia, P. (1992). Trends in gambling: The pari-mutuel racing industry and effect of state lotteries, a new market definition. Journal of Cultural Economics, 16(2), 51-62.

Morley, J. C. (2007). The slow adjustment of aggregate consumption to permanent income. Journal of Money, Credit and Banking, 39(2-3), 615-638.

Muraven, M., \& Baumeister, R. F. (2000). Self-regulation and depletion of limited resources: Does selfcontrol resemble a muscle? Psychological Bulletin, 126(2), 247-259.

Newey, W. K., \& West, K. D. (1987). A simple, positive semi-definite heteroskedasticity and autocorrelation consistent covariance matrix. Econometrica, 55(3), 703-708. 
Nower, L., \& Blaszczynski, A. (2006). Impulsivity and pathological gambling: A descriptive model. International Gambling Studies, 6(1), 61-75.

Paap, R., \& van Dijk, H. K. (2003). Markov Trends in Possibly cointegrated series. Journal of Business and Economic Statistics, 21(4), 547-562.

Palumbo, M., Rudd, J., \& Whelan, K. (2006). On the relationships between real consumption, income, and wealth. Journal of Business and Economic Statistics, 24(1), 1-11.

Raab, C., \& Schwer, R. K. (2003). The short- and long-term impact of the Asian financial crisis on Las Vegas Strip baccarat revenues. Hospitality Management, 22, 37-45.

Radding, A., \& Hume, S. (1991). Old lotteries freshen up. Advertising Age, 62, 12.

Richard, B. (2010). Diffusion of an economic development policy innovation: Explaining the international spread of casino gambling. Journal of Gambling Studies, 26(2), 287-300.

Rose, I. N. (2010). The lingering effects of the great recession. Gambling and the Law, 14(9), 651-654.

Sargent, T. J. (1978). Rational expectations, economic exogeneity and consumption. Journal of Political Economy, 86(4), 673-700.

Schwartz, G. (1978). Estimating the dimension of a model. Annals of Statistics, 6(2), 461-464.

Shanklin, B. (2010). Racing popularity and short attention spans. Horse Racing Business. February. http://www.horseracingbusiness.com/racings-popularity-and-short-attention-spans-3626.htm.

Sharpe, L., \& Tarrier, N. (1993). Towards a cognitive-behavioral theory of problem gambling. The British Journal of Psychiatry, 162, 407-412.

Siegel, D., \& Anders, G. (2001). The impact of Indian casinos on state lotteries: A case study of Arizona. Public Finance Review, 28(2), 139-147.

Tenkel, S. (1970). Hard times: An oral history of the great depression. New York: Pantheon.

Thalheimer, R. (1998). Parimutuel wagering and video gaming: A racetrack portfolio. Applied Economics, 30, 531-544.

Thalheimer, R., \& Ali, M. M. (2008). The demand for casino gambling with special reference to a smoking ban. Economic Inquiry, 46(2), 273-282.

Tripoli, L. (2009). Wasn't the gambling law business supposed to be recession-proof? Gaming Law Review and Economics, 13(1), 23-26.

Wiebe, J. M. D., \& Cox, B. J. (2005). Problem and probable pathological gambling among older adults assessed by the SOGS-R. Journal of Gambling Studies, 21(2), 205-221. 